\title{
Design of Renewable Energy System for a House in St. John's, Canada
}

\author{
Uday G. Khadodra, Habibur Rahaman, and Mohsin Jamil
}

\begin{abstract}
During this period of rising energy demand, utility companies are at a certain point in time, unable to satisfy the overall requirements of their entire consumer population. During this kind of situation, the system, which is, at a microscale, can also refer to a zero-energy building, which can also be very prominent in solving this problem. Another thing is that cries of non-renewable energy sources and most of the utility companies are majorly dependent on that kind of energy source, and it keeps along with issues of global warming. A renewable energy-based power system can solve this issue. In this paper, the solution to this problem by introducing the microscale installation of a renewable energy source at the residential level has been presented. For that here, the area selected for this project is located in St. John's, Newfoundland and Labrador, CANADA. Newfoundland is an island; hence, the proposed system would be beneficial here. Building this kind of system is the process of designing, selecting, and calculating the energy demand of equipment and, at last, synchronizing it with the grid to make it as zero energy building. This process depends upon a range of variables, including geographical location, load requirement, and solar irradiation. The required demand, system modeling, simulation, and techno-economic analysis are carried out by BEopt, HOEMR, and MATLAB software.
\end{abstract}

Keywords-Designing, Sizing, Renewable energy system, Photovoltaic system, Grid-tied, Canadian house.

\section{INTRODUCTION}

Energy is one of the driving forces for social and economic growth and the primary demand of nations. The sun provides the energy required in our solar system to sustain life. The planet receives enough energy from the sun in one hour to fulfill its energy needs for nearly a year. For many reasons, photovoltaic is an attractive alternative to the traditional electrical source: it is safe, silent and non-polluting, renewable, highly flexible. Its capacity can be increased incrementally to suit gradual load growth, and reliable with minimum failure levels and projected service life of 2030 years[1]. No specialized training is needed to operate; it does not include moving parts; it is highly durable and practically maintenance-free, and it can be mounted almost anywhere. Sunlight intensity reaching the Earth varies with time of day, Season, location, and atmospheric condition. The total energy is called irradiation on a daily or annual basis, which shows the power of light [2]. Solar irradiation is measured in $\mathrm{kWh} / \mathrm{m}^{2}$. As different geographical regions experience different weather patterns[3], the design also varies with the location for tilt angle and orientation. Photovoltaic panels gather more energy if they are mounted on a real-time tracker that tracks the sun's movement[4]; however, it's a costly operation. Photovoltaic is usually mounted on a fixed position with an angle, and this angle varies with the seasonal variations for cost effectiveness[3]. There is much research published on designing the renewable energy system for domestic use. The idea of this paper is to introduce the sizing or designing of renewable energy systems for Canadian house. Here all design consideration is taken as per the geographical condition of St. John's. In St. John's, the average annual snow rate is $322 \mathrm{~cm}[5]$ and annual average wind speed of $24 \mathrm{~km} / \mathrm{h}$ , and sometimes it goes up to $131.4 \mathrm{~km} / \mathrm{h}$. This high wind speed [5] can cause severe problems in wind turbine operation. Another issue is that here the design is for domestic use, and wind turbines generate too much noise, which can create a problem for people who live near in that community[6]. By taking count of difficulties associated with wind-based power generation, the best possible solution for this site location, solar-based power generation, is a wise choice.

This paper is presenting the ideology to design a solarbased power generation system for Canadian houses. It consists of annual energy consumption of the house, sizing of solar P.V., and Controlling of the system, which is done by P.I. Control.

\section{LITERATURE REVIEW}

The hybrid power system is a fast-growing research area. This technology is using residential, commercial, industrial load as well, and research is going on to be effectively incorporated in automobiles [6],[7]. Renewable energy options include solar, wind, tidal, geothermal, wave power, and biomass[8]. They are enduring, regenerate themselves naturally, and are environmentally friendly, which is why they are called green energy resources. Over time, there is a gradual decline of non-renewable energy resources like coal, oil, gas, etc. The key feature of the hybrid renewable energy system[9] is to combine two or more renewable energy generation to mitigate the capacity, reliability, pollution, and economic constraints of a single source of renewable energy. The approach aims to find the configuration among a collection of system components that meet the desired system reliability needs with the lowest cost benefits[10].

In the field of renewable energy resources and a hybrid system of research and development has been accomplished. The off-grid only hybrid system has been planned and suggested for areas where there are either water, wind, or both are available. A wind turbine works effectively for the wind speed of $15 \mathrm{~m} / \mathrm{s}$ or more, while solar power helps to operate the device uninterruptedly in the case of insufficient wind power. In other words, solar photovoltaic provides maximum nighttime energy. But the autonomous hybrid system is not reliable. Hence it is highly recommended on the grid system. The system is connected to the A.C. grid in an on-grid hybrid system, so that renewable energy allows the national grid to supply the consumer with electricity. Nonetheless, in areas where a constant supply from the A.C. grid is not sufficient, the backup generator must be linked to the system that will supply electricity when there is no A.C. supply from the 
primary source[8]. The most appropriate method for domestic use must have a hybrid power system consisting of; a solar power system, a wind power system, an A.C. grid main supply, and also a D.G. set for backup supply.

Research and development have been done on the control and management of the on-grid hybrid power system. Still, there has been insufficient work done to make this technology useful for domestic users. But still, some researchers are working on the controlling side [5]. They suggested that the mixture of neuro and fuzzy logic can be implemented in the wind turbine for speed control[11], where the controller was able to adjust the speed of the rotor according to the wind speed in different areas. These results indicate the rapid response to the change in wind speed, and consequently, in a shorter period, the rise in power generation.

Similarly, other researchers put forward an adaptive technique to improve the efficiency of P.V. systems by using the Adaptive-Neuro- Fuzzy inference system based on the maximum power point tracking (MPPT) system under any atmospheric condition[11] [5]. The results compare (Perturb \& Observe) P\&O-MPPT method and ANFIS by having better MPPT performance with ANFIS, i.e., by tracking maximum power with rapid follow-up, speed, and high accuracy under all irradiance conditions [6]. A fuzzy logic controller coupled with a power electronic device to ensure that the solar power input stabilizes the load-side output voltage. The simulation is done on the performance of open-loop fuzzy logic controllers[12] and closed-loop fuzzy logic controllers. The results show that the closed-loop fuzzy logic controller is more accurate with different quantities such as $0 \%$ peak overshoot, settling time $<0.5$, and min steady-state error. The controller also maintains the constant output voltage regardless of the solar irradiance, load value, and temperature disturbances. Authors in [13] tried to implement a new converter, i.e., a Cuk converter that merges with renewables and uses a fuzzy logic controller (ANFIS)[14]. The Cuk converter is a hybrid of a buck-boost converter but has an opposite polarity on the other side (inversion converter). The results have increased the performance of the P.V. system, and the cost of implementation of the system is lower as no sensors have been used in the solar irradiance system. The Cuk converter was also examined.

In this paper, a P.V. based renewable energy system design and techno-economic analysis have been conducted step by step for a Canadian single-family house.

\section{GeOGRAPHICAL LOCATION}

First, the house chosen for this project was 82, Larkhall Street, St. John's, NL, Canada N 47 34' 4.2947" and W $52^{\circ}$ $45^{\prime} 0.6223$ " with a total area of $141.75 \mathrm{~m}^{2}$. The following Fig. 1 shows the satellite view of the location.

\section{SOLAR RESOURCES}

St. john's is the easternmost part of Canada. Annually St. John's has 949 hrs. of sunlight, which is adequate to install a solar P.V. system for a house. The typical Solar Global horizontal Index for St. John's can be seen in Fig. 3.

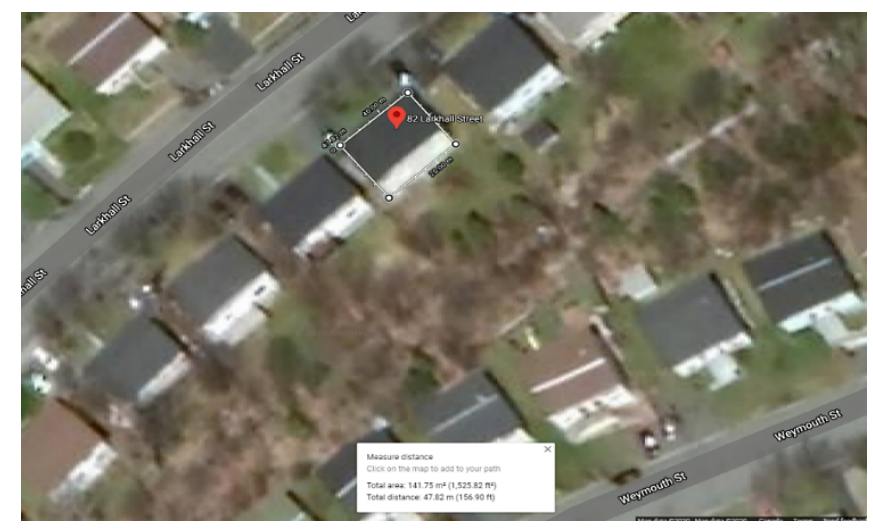

Fig. 1 Site selection

It can be seen in Fig. 3, that the solar irradiance varies from $1.02 \mathrm{kWh} / \mathrm{m}^{2}$ to $5.14 \mathrm{kWh} / \mathrm{m}^{2}$ per day throughout the year. The clearness index ranges from 0.39 to 0.496 throughout the year. The overall stats show that St. John's is an excellent location for the implementation of a solar system. The below Fig. 2 depicts the information of average solar irradiation for different months with different tilt angles, i.e., South-facing vertical $\left(\right.$ tilt $\left.=90^{\circ}\right)$, South-facing tilt=latitude, South-facing tilt $=$ lat $+15^{\circ}$, South-facing tilt $=$ lat $-15^{\circ}$, and Two-axis suntracking.

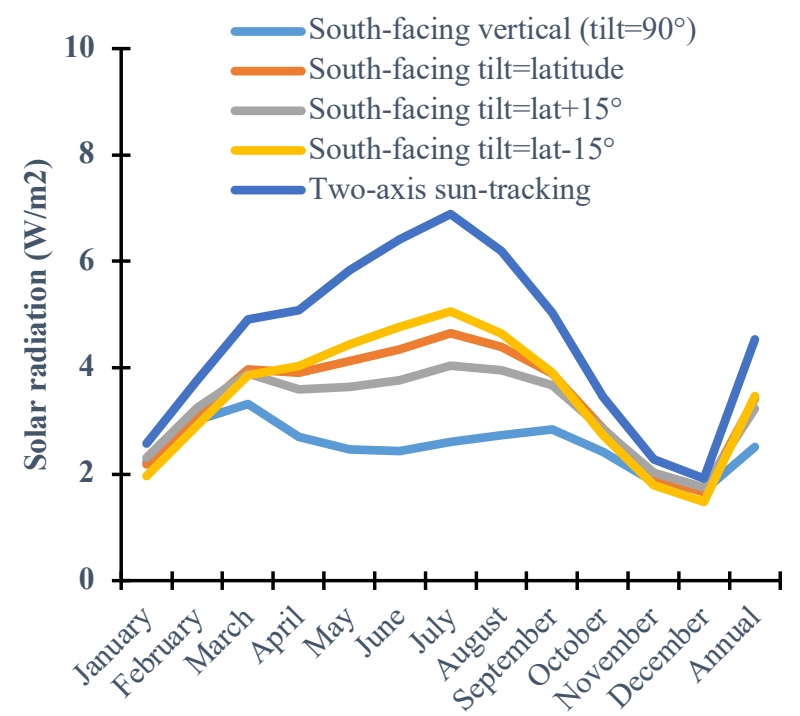

Fig. 2 Solar irradiation for St. John's

As can be seen from the above chart that Solar P.V. can generate maximum power if it has a two-axis tracking system, which gives $4.53 \mathrm{kWh} / \mathrm{m}^{2}$, but that system is way expensive. So, the remaining useful information from the chart is that when the tilt angle is equal to latitude- $15^{\circ}$ with the south face, it will give $3.47 \mathrm{kWh} / \mathrm{m}^{2}$, which is the second-highest generation by solar P.V. 


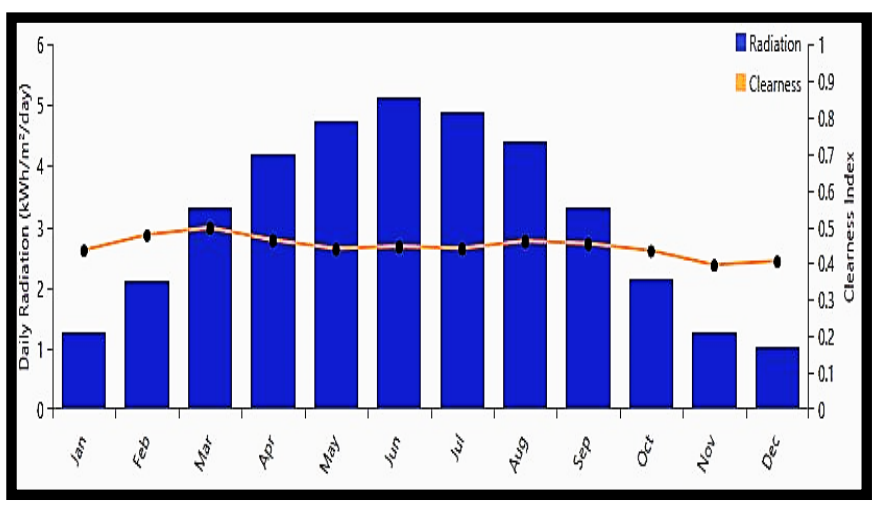

Fig. 3 Solar GHI as in HOMER

Tilt Angle for proposed system $=$ latitude -15

Tilt Angle for proposed system $=32$

\section{SySTEM DESCRIPTION}

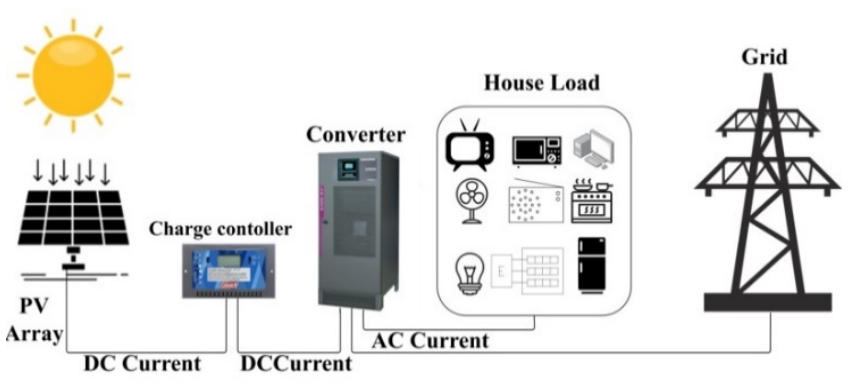

Fig. 4 General layout of the proposed system

The general design of the proposed method can be seen from the above Fig. 4. This system mainly consists of P.V. modules, Electrical load (House), control unit (Charge controller, converter), and grid.

\section{A. P.V. Module}

P.V. modules have the D.C Electrical output power, nonmoving parts, and no burning contaminants. P.V. systems are modular, giving it the benefit of being able to increase its size even after deployment. It is versatile, simple, and quickly organized and designed into an array or photovoltaic system.

\section{B. Control Unit}

The Control Unit is the heart of the entire system; this unit can do all control of the system. Controller performance can affect the life and reliability of the system. Here for this project, the proportional-integral (P.I.) controller is used to controlling the system. P.I. The controller has been used to track almost any process one might think of, from aerospace to motion control, from slow to fast system. P.I.controller is regularly balanced by system configuration changes and operating point variability. Adaptive P.I. Control avoid timeconsuming manual adjustment by providing optimal P.L. controller setting automatically when system dynamics or operating points change. This controller is used to control the inverter switching input with a constant or steady output, which can be delivered to the grid or load. Mainly there are two types of an inverter voltage source or current source inverter. These inverters are typically output inverters. The voltage input inverter input is a rigid D.C. voltage supply that can be used as a battery or as a controlled rectifier for both single-phase and three-phase input voltage inverter in industries. The switching mechanism can be a standard resistor for MOSFET, Thyristor, or switch. PWM method is used to control the switching pules of the switch.

\section{Grid}

The power grid or electrical grid is an integrated grid for the delivery of electricity from producer to consumers.it has electric power generating station, electrical substations for stepping up electrical voltage for transmission or down for distribution.

\section{SIZING OF THE SYSTEM}

System sizing is the method of determining the correct voltage and current rating of each part of a photovoltaic system to satisfy the electrical demand at the load and, at the same time, measuring the total system price from the design phase to the full operating system including shipping and labor.

\section{A. Load calculation}

The very first step to designing this kind of system is to determine the total annual energy usage in this step, all residential item which consumes electricity must be identified with its rating and working hours. Here, it is known the fact that house heating is a paramount need of the Canadian house, which directly correlated with energy consumption. The architecture, insulation types of the house have also been taken into account. For that, the building energy optimization tool (BEOpt) software is used. BEopt software can calculate the monthly and annual electrical demand. The input parameters of this software are plugin load, lighting load with general operating hours (high during the peak time and low during off time), type of heating system, and how much energy it would take during a different time of the year, weather condition of selected data. BEopt also considers the orientation of the house for nature ventilation. The modeling of the house has done in BEpot with exact site location with consideration of different factors affecting the electrical load.

As can be seen from above Fig. 5, energy requirements are high up to $3300 \mathrm{kWh} /$ month during wintertime because of harsh weather conditions St. John's has, and low up to $1000 \mathrm{kWh} /$ month during summertime. Fig. 6 shows the electrical output of BEopt. The actual energy consumption of the home is $24,355 \mathrm{kWh} / \mathrm{yr}$, and the simulation result is $23,174 \mathrm{kWh} / \mathrm{yr}$. Hence, total energy consumption is almost the same, so it will not affect the design of the system.

\section{B. Array sizing}

1) Mathematical sizing;

- Avg. the annual load is $23170.2 \mathrm{~kW} / \mathrm{yr}$

- Avg. the daily load is $63.48 \mathrm{~kW} / \mathrm{d}$

- Avg. the hourly load is $2.6 \mathrm{~kW} / \mathrm{h}$ 


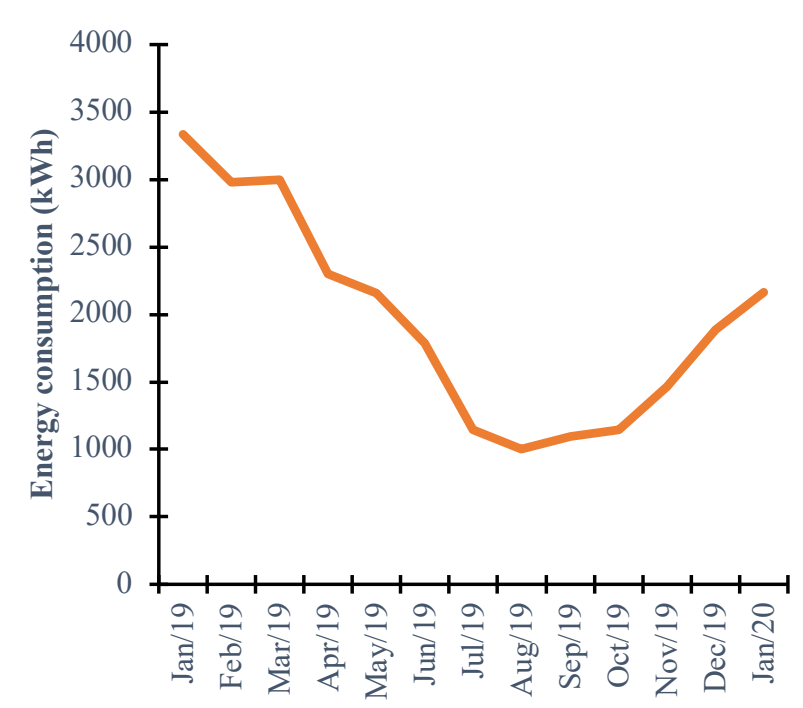

Fig. 5 Energy used in kWh (As per utility bill)

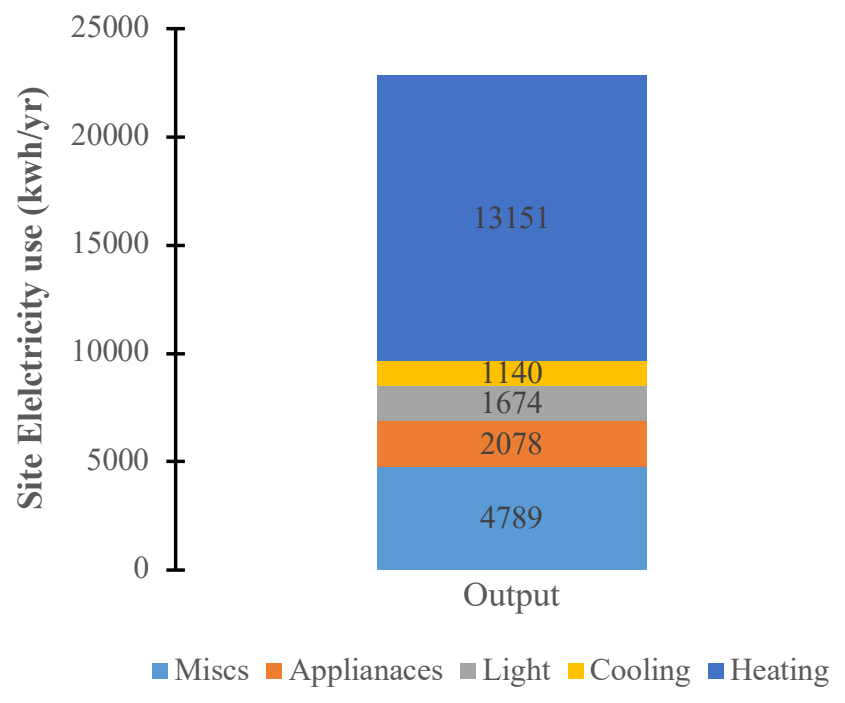

Fig. 6 BEopt simulation output (Electrical)

The equation for Array size is given by,

(avg. annual load) / (avg. annual solar irradiation $\times$ efficiency of module $\times$ Stationary array correction factor)

No. of modules requires $=($ overall capacity $) /($ rated capacity of one module)

From equation three, the total number of modules required can be found out to be 200 . The modules selected for this site installation is Canadian solar max power 340P because it is a local brand. Hence, there would be a quick maintenance service and less shipping charges.

From the datasheet of Canadian solar Maxpower 340P, the total area required for one module is turned out to be 1.74 $\mathrm{m}^{2}$. Therefore, the whole area needed for the entire system can be calculated by,

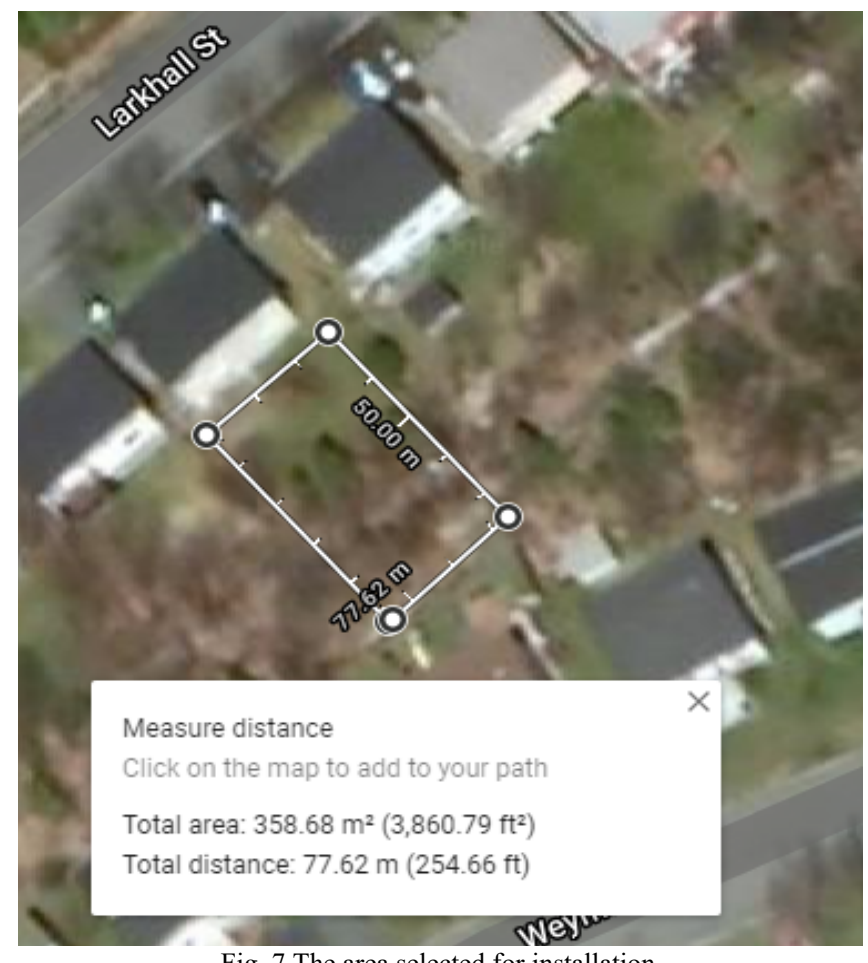

Fig. 7 The area selected for installation

Area required for one module $\times$ No. of modules required

As per the calculation, 50 modules are connected in one string with four parallel, by this means current would be minimum; hence the area of the conductor would be reduced, eventually cost will decrease. This whole system can be installed in the back yard of the house, which has enough space, Fig can see this. 7.

For optimum sizing, the overall average energy demands each day by the output of system components to archive the daily energy requirement from the solar array.

$$
E_{r}=\frac{\text { daily avg energy consumption }}{\text { product of component's ef ficiency }}
$$

$$
=\frac{E}{\eta_{\text {overall }}}
$$

The preliminary results are separated by the average sunlight hours a day for the geographical area.

$$
\begin{gathered}
P_{P}=\frac{\text { daily energy requirement }}{\text { minimum peak sun }- \text { hours per day }} \\
=\frac{E_{r}}{T_{\min }}
\end{gathered}
$$

The overall current needed can be determined by dividing the peak power by the D.C. voltage of the device.

$$
\begin{gathered}
I_{D C}=\frac{\text { Peak power }}{\text { System } D C \text { voltage }} \\
=\frac{P_{P}}{V_{D C}}
\end{gathered}
$$

2) Array Sizing using PV WATT calculator by NREL: 
For very early studies of a possible location for a photovoltaic system using crystalline photovoltaic silicon modules, the PV WATT calculator is the most suitable online software. The output Figures that are the measurement of the PV WATT calculator do not take into account many factors that are important to the design of the photovoltaic system.

As per equation, 1 The tilt angle is set to 32 to get maximum output from the system. The next step is to select an area for the proposed method and then select what kind of system you what to install, i.e., Fixed or tacking. Here a fixed mounted system is selected

Before commencing simulation, the PVWatt calculator displays the details selected for the proposed system for confirmation, after that simulation PVWatt calculator would predict the monthly generation from the proposed method. The output for this system can be looked at by Fig. 8. The expected output for the system is $61,998 \mathrm{kWh} / \mathrm{yr}$, which is more than the load requirement, but this remaining energy can be useful to make zero energy building.

\section{Charge controller sizing}

As the purpose of the charge controller is to regulate the flow of current. A charge regulator must be able to tolerate both the maximum current of the load. The charge regulator size can be accomplished by averaging the short circuit current of the modules connected in parallel by a safety factor. Rated current of charge controller can be given as,

$$
I=I_{S} * N_{P} * F_{\text {safe }}
$$

\begin{tabular}{|c|c|c|c|}
\hline \multicolumn{4}{|l|}{ RESULTS } \\
\hline Month & $\begin{array}{l}\text { Solar Radiation } \\
\left(\mathrm{kWh} / \mathrm{m}^{2} / \text { day }\right)\end{array}$ & $\begin{array}{l}\text { AC Energy } \\
(\mathrm{kWh})\end{array}$ & $\begin{array}{l}\text { Value } \\
\text { (\$) }\end{array}$ \\
\hline January & 1.86 & 2,721 & $N / A$ \\
\hline February & 2.81 & 3,708 & N/A \\
\hline March & 4.06 & 5,767 & $N / A$ \\
\hline April & 5.12 & 6,823 & N/A \\
\hline May & 5.34 & 7,220 & $N / A$ \\
\hline June & 5.56 & 7,202 & N/A \\
\hline July & 5.46 & 7,050 & N/A \\
\hline August & 5.04 & 6,584 & N/A \\
\hline September & 4.50 & 5,781 & $N / A$ \\
\hline October & 2.99 & 4,101 & N/A \\
\hline November & 2.01 & 2,757 & N/A \\
\hline December & 1.58 & 2,284 & N/A \\
\hline Annual & 3.86 & 61,998 & 0 \\
\hline
\end{tabular}

Fig. 8 Output of P.V. watt calculator

The safety factor is used to ensure that the maximum current generated by the array that may surpass the tabulated value. The controller required is equivalent to the array short circuit current divided by Amps for each controller;

$$
N_{\text {con }}=\frac{I}{\text { Amps each controller }}
$$

\section{Inverter sizing}

The actual power can be drawn from the system that will operate consistently must be calculated as a first step when sizing the inverter. The total control runs through the system is $63.14 \mathrm{kWh} /$ day; hence inverter must handle this much power. Inverter SUN-ES66KTRULIS by SOCOMEC innovative power solution of $66 \mathrm{~kW}$ is the perfect suit for this proposed design.

\section{7. SiMULATION RESUltS OF HOMER}

HOMER is a model for static simulation. It will try to simulate a feasible system for all possible equipment combinations which you wish to consider. HOMER can affect hundreds or even thousands of methods, depending on how the system is set up. HOMER simulates an entire year of operation of a hybrid microgrid in time intervals from one minute to one hour.

Here the system is set up as per the sizing of the proposed order; the schematic layout of the system can be seen in Fig. 9.

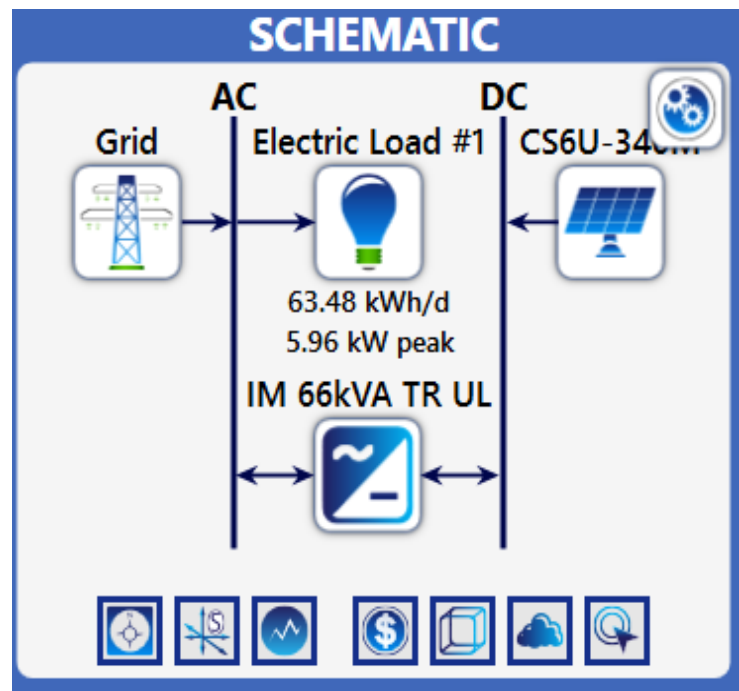

Fig. 9 Schematic diagram of the system

Table 1 Production summary

\begin{tabular}{ccc}
\hline Component & $\begin{array}{c}\text { Production } \\
\text { (kWh/yr) }\end{array}$ & Percent \\
\hline $\begin{array}{c}\text { CanadianSolar MaxPower CS6U- } \\
\text { 340M } \\
\text { Grid Purchases }\end{array}$ & 84,035 & 87.2 \\
Total & 12,381 & 12.8 \\
\hline
\end{tabular}




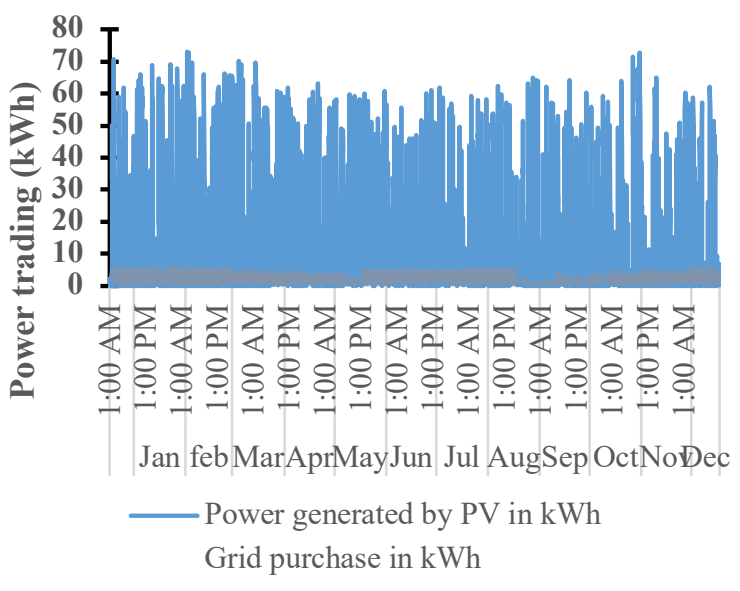

Fig. 10 Electrical output by HOMER

As can be seen in Fig. 10 and Table 1 designed system is generating $87.2 \%$ and only $12.8 \%$ purchasing from the grid during the cloudy days. Excess energy is $19 \%$, which can be negligible while designing a large system.

Table 2 Annualized Cost

\begin{tabular}{|c|c|c|c|c|c|}
\hline Name & $\begin{array}{l}\text { Capit } \\
\text { al }\end{array}$ & $\begin{array}{c}\text { Operati } \\
\text { ng }\end{array}$ & $\begin{array}{c}\text { Replaceme } \\
\text { nt }\end{array}$ & $\begin{array}{c}\text { Salva } \\
\text { ge }\end{array}$ & Total \\
\hline $\begin{array}{c}\text { CanadianSo } \\
\text { lar } \\
\text { MaxPower } \\
\text { CS6U-340M }\end{array}$ & $\$ 2,790$ & $\$ 4,008$ & $\$ 0.00$ & $\$ 0.00$ & $\$ 6,799$ \\
\hline Grid & $\$ 0.00$ & $-\$ 2,750$ & $\$ 0.00$ & $\$ 0.00$ & $\$ 2,750$ \\
\hline $\begin{array}{c}\text { SUNSYS } \\
\text { PCS }^{2} \text { IM } \\
\text { 66kVA TR } \\
\text { UL }\end{array}$ & $\begin{array}{c}\$ 180.3 \\
8\end{array}$ & $\$ 372.27$ & $\$ 131.39$ & $\begin{array}{c}- \\
\$ 17.81\end{array}$ & $\begin{array}{c}\$ 666.2 \\
3\end{array}$ \\
\hline System & $\$ 2,971$ & $\$ 1,631$ & $\$ 131.39$ & $\begin{array}{c}- \\
\$ 17.81\end{array}$ & $\$ 4,715$ \\
\hline
\end{tabular}

to the grid, from that system got $2750 \mathrm{CAD}$, this makes the system more economical. The total net present cost of the system is turning out to be $64,229.05 \mathrm{CAD}$, and the operating cost is 1744.37 CAD.

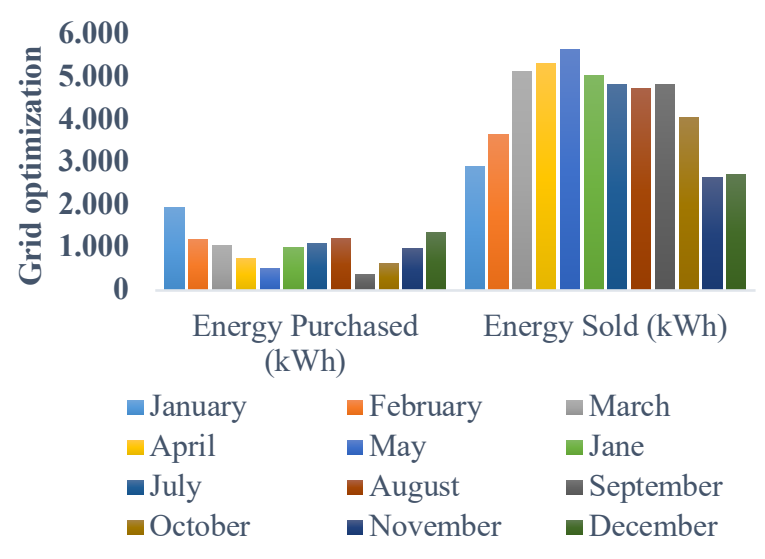

Fig. 12 Grid optimization results

VIII. MATLAB SIMULATION

MATLAB is an interactive system whose fundamental element of data is an array that needs no dimensioning. This allows users to solve many technical computing problems in a fraction of

the time it would take to write a program in a non-interactive scalar language like $\mathrm{C}$ or Fortran, particularly those with matrix and vector formulation. MATLAB is used for realtime simulation of a designed system with a grid for integration. Grid power providing a reference signal to PWM to generate to triggering pulses of a switch to Operate and convert D.C. input power to Synchronized A.C. power. The controlling logic behind this system is PI Control. Fig. 11 shows the simulation diagram for the proposed system.

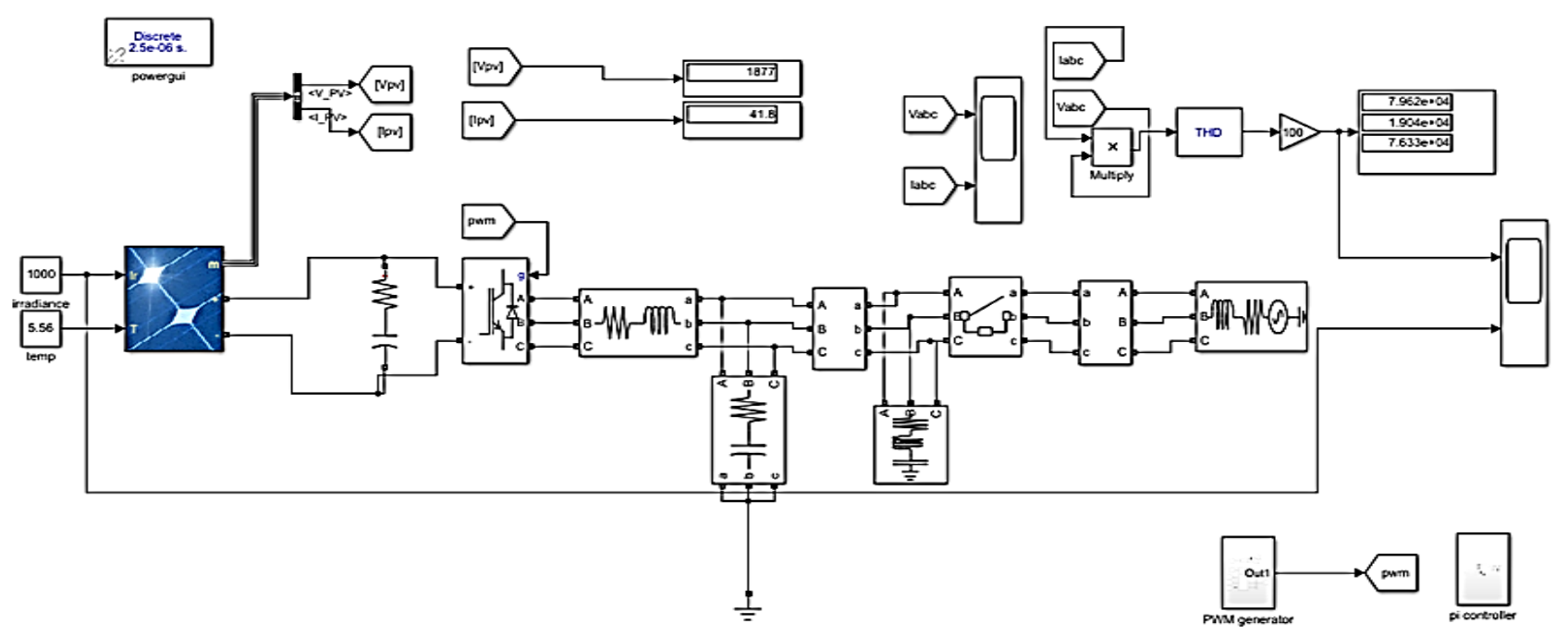

Fig. 11 Matlab simulation model

From Table 2, the annual cost of the system turns out to be 4,715 CAD. Canadian solar costs up to 6,799 CAD, but here, due to excess electricity produced by the P.V., is selling
Fig. 12 and 13 show the output waveforms of the proposed system. Fig. 12 depicts the output waveforms of the proposed 
method as, from Fig. There is a smooth A.C. voltage, which is the requirement of any domestic system as with current. Hence, the design system is feasible for practical implementation.

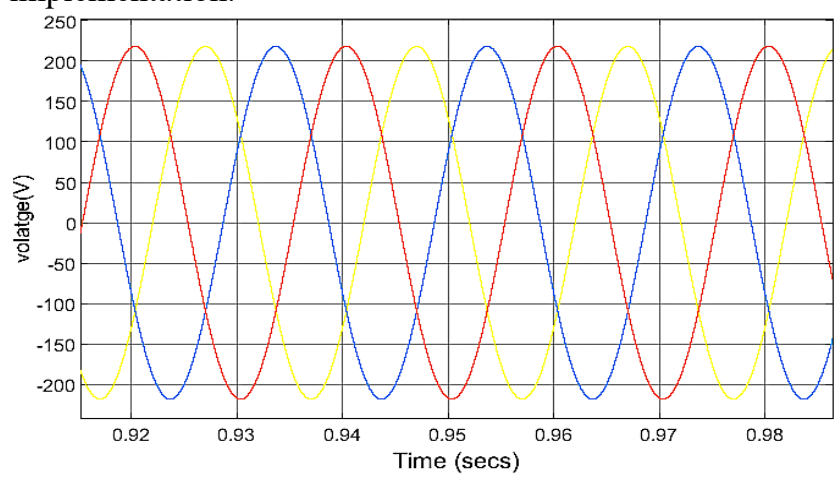

Fig. 13 Output voltage waveforms

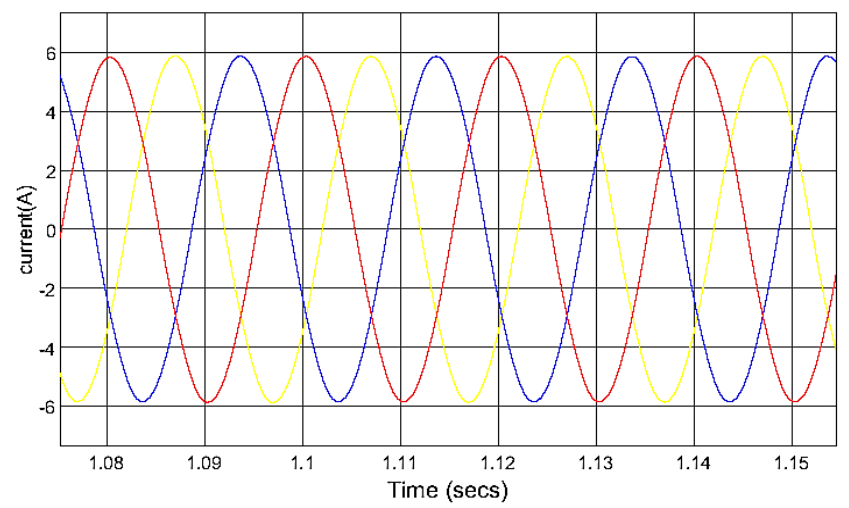

Fig. 14 Output current waveforms

\section{CONCLUSION}

The methodology for deciding the optimum size of the solar array is provided. This is a valuable method to develop a renewable energy system for a house and assess the efficiency and expense of the order before the actual system is installed. The same exercise was performed for a house selected which is located in St. john's, Newfoundland and Labrador, CANADA has annual average solar irradiation of $3.2 \mathrm{kWh} / \mathrm{m}^{2} /$ day and generating $84,035 \mathrm{kWh} / \mathrm{yr}$ (refer Table 1), which is adequate for a grid-tied solar P.V. system to build zero energy building. That can be seen in Table 2 and Fig. 10; the proposed system selling $51,710 \mathrm{kWh} / \mathrm{yr}$ while the load is $23,170 \mathrm{kWh} / \mathrm{yr}$, which is more than load consumption, and the unmet load is also zero. Hence, the proposed system never faces an energy breakdown.

This paper presents the procedures used in the design and selection of the equipment of the based photovoltaic system as per the watt-hour demand. It also discussed the factors which affect the design and sizing of each material used in the system. The same method could be used and adapted to application with an extensive energy system and could also be used for different locations. Still, the design constraints should be changed as per the area.

\section{REFERENCES}

[1] H. Liao, J. Peng, H. Li, C. Lyu, and Z. Huang, "Energy Sharing of Zero-Energy Buildings: A Consensus-Based Approach," IEEE Access, vol. 7, no.11, pp. 62172-62183, 2019.

[2] M. H. Rahaman and T. Iqbal, "A Comparison of Solar Photovoltaic and Solar Thermal Collector for Residential Water Heating and Space Heating System," Eur. J. Eng. Res. Sci., vol. 4, no. 12, pp. 4147, 2019.

[3] U. Fesli, R. Bayir, and M. Özer, "Design and Implementation of a Domestic Solar-Wind Hybrid Energy System," in 2009 International Conference on Electrical and Electronics Engineering - ELECO, pp. 27-33, 2009.

[4] M. A. Hannan et al., "A Review of Internet of Energy Based Building Energy Management Systems: Issues and Recommendations," IEEE Access, vol. 6, pp. 38997-39014, 2018.

[5] M. H. Radhi, E. J. Mahdi, and A. K. Mftwol, "Design and Performance Analysis of Solar P.V. System Size $2.56 \mathrm{kWp}$," in 2019 4th Scientific International Conference Najaf (SICN), pp. 70-73, 2019.

[6] K. Amara et al., "Improved Performance of a P.V. Solar Panel with Adaptive Neuro Fuzzy Inference System ANFIS based MPPT," in 2018 7th International Conference on Renewable Energy Research and Applications (ICRERA), pp. 1098-1101, 2018.

[7] M. H. Mahlooji, H. R. Mohammadi, and M. Rahimi, "A Review on Modeling and Control of Grid-Connected Photovoltaic Inverters with LCL Filter," Renew. Sustain. Energy Rev., vol. 81, no. 7, pp. 563-578, 2018.

[8] C. Liu, K. T. Chau, and X. Zhang, "An Efficient Wind-Photovoltaic Hybrid Generation System Using Doubly Excited PermanentMagnet Brushless Machine," IEEE Trans. Ind. Electron., vol. 57, no. 3, pp. 831-839, 2010.

[9] Md. H. Rahaman and M. R. I. Sheikh, "Stability Improvement of Power System By Using SVC With PI And P.D. Controller," vol. 5, no. 10 , pp. 111-118, 2013.

[10] Md. H. Rahaman, M. Asaduz-Zaman, and S. Shawon, "Optimum Economic Scheduling Strategy of Islanded Multi-Microgrid," vol. 7, no. 5, pp. 01-08, 2018.

[11] N. Priyadarshi, S. Padmanaban, J. B. Holm-Nielsen, V. K. Ramachandaramurthy, and M. S. Bhaskar, "An Adaptive NeuroFuzzy Inference System Employed Cuk Converter for P.V. Applications," in 2019 IEEE 13th International Conference on Compatibility, Power Electronics and Power Engineering (CPEPOWERENG), pp. 1-5, 2019.

[12] H.-S. Ko and J. Jatskevich, "Power Quality Control of Wind-Hybrid Power Generation System Using Fuzzy-LQR Controller," IEEE Trans. Energy Convers., vol. 22, no. 2, pp. 516-527, 2007.

[13] Z. Liang, R. Guo, J. Li, and A. Q. Huang, "A High-Efficiency PV Module-Integrated DC/DC Converter for P.V. Energy Harvest in FREEDM Systems," IEEE Trans. Power Electron., vol. 26, no. 3, pp. 897-909, 2011.

[14] N. Priyadarshi, S. Padmanaban, J. B. Holm-Nielsen, F. Blaabjerg, and M. S. Bhaskar, "An Experimental Estimation of Hybrid ANFISPSO-Based MPPT for P.V. Grid Integration Under Fluctuating Sun Irradiance," IEEE Syst. J., vol. 14, no. 1, pp. 1218-1229, 2020. 